\title{
Effects of compound organic acid calcium on growth performance, hepatic antioxidation and intestinal barrier of male broilers under heat stress
}

\author{
Junna He ${ }^{1}$, Lianxiang Ma', Jialing Qiu', Xintao Lu', Chuanchuan Hou', Bing Liu ${ }^{1,2}$, and Dongyou Yu${ }^{1}$,*
}

\begin{abstract}
* Corresponding Author: Dongyou Yu Tel: +86-571-88982107, Fax: +86-571-88982107, E-mail: dyyu@zju.edu.cn
\end{abstract}

${ }^{1}$ College of Animal Science, Key Laboratory of Animal Nutrition and Feed in East China, Ministry of Agriculture, Zhejiang University, Hangzhou, 310058, China

${ }^{2}$ State Key Laboratory of Food Science and Technology, and Synergetic Innovation Center of Food Safety and Nutrition of Jiangnan University, Wuxi, Jiangsu 214122, China

ORCID

Junna He

https://orcid.org/0000-0003-1805-2434

Lianxiang Ma

https://orcid.org/0000-0001-7554-9047

Jialing Qiu

https://orcid.org/0000-0002-3440-7488 Xintao Lu

https://orcid.org/0000-0003-0051-8929

Chuanchuan Hou

https://orcid.org/0000-0001-6731-5611

Bing Liu

https://orcid.org/0000-0003-0451-7341

Dongyou Yu

https://orcid.org/0000-0002-8350-3126

Submitted Apr 3, 2019; Revised Jun 11, 2019; Accepted Aug 11, 2019
Objective: The aim of this study was to evaluate the effects of compound organic acid calcium (COAC) on growth performance, hepatic antioxidant status and intestinal barrier of male broilers under high ambient temperature $\left(32.7^{\circ} \mathrm{C}\right)$.

Methods: Nine hundred healthy one-d-old Cobb-500 male broiler chicks were randomly assigned into three groups with six replicates of 50 birds each. A basal diet supplemented with $0 \%$ (control), $0.4 \%$ and $0.8 \% \mathrm{COAC}$, respectively were fed to birds for 6 weeks. All treatments were under high ambient indoor temperature of $32.7^{\circ} \mathrm{C}$, and had a constant calcium and available phosphorus ratio.

Results: The results showed that, compared with control, the average daily gain of broilers in $0.4 \%$ and $0.8 \%$ was significantly increased and the ratio of feed to gain in in $0.4 \%$ and $0.8 \%$ was significantly decreased at 1 to 21,22 to 42 and 1 to 42 days of age $(\mathrm{p}<0.05)$. Compared with control, $0.8 \%$ COAC slightly decreased $(\mathrm{p}=0.093)$ the content of malondialdehyde in liver at 42 days of age while $0.4 \%$ COAC significantly decreased $(\mathrm{p}<0.05)$ the activity of alkaline phosphatase. Furthermore, 0.4\% COAC significantly enhanced the intestinal barrier function via increasing jejunal and ileal ocln transcription, promoting jejunal mucin 2 transcription at 42 days of age $(\mathrm{p}<0.05)$, and decreasing jejunal toll-like receptor 2 (TLR-2) and ileal TLR-15, inducible nitric oxide synthase compared with control group $(\mathrm{p}<0.05)$. Whereas, no significant differences on the transcription of interleukin- $1 \beta$ in jejunum and ileum were observed among three treatments ( $p>0.05$ ). Overall, heat stress caused by high natural environment temperature may induce the damage to hepatic antioxidation and intestinal barrier. Conclusion: Dietary inclusion of COAC can improve the tolerance of broilers to thermal environment through the modification of antioxidative parameters in liver and the mRNA expression of genes in intestinal barrier, resulting in an optimal inclusion level of $0.4 \%$.

Keywords: Growth Performance; Compound Organic Acid Calcium; Antioxidation; Intestinal Barrier; Heat Stress; Broiler

\section{INTRODUCTION}

Heat stress caused by high ambient temperature and relative humidity is one of the most severe issues in commercial poultry production due to its serious damage on performance, immunity and antioxidant status of broilers [1], gene expression [2], and body temperature at hatching [3], culminating in economic losses. An unreliable housing environment, especially with the additional challenge by the rising temperature due to global warming, could lead to a disruption of the boilers' body temperature control with dysfunction in the respiratory system and circulation [4]. There are numerous poultry factories in regions across China that suffer from hot summers with at least $30^{\circ} \mathrm{C}$ for a few hours every day, which have been experiencing technical limitations in attempting make an economic profit. Broilers 
in these factories would be more vulnerable to heat increments compared to younger birds due to their increased of body mass and development of feather layers as they grow [3]. In order to solve those increasing problems caused by hot climate, different methods have been carried out [5]. Excluding lowering stocking density, dietary supplementation of probiotics, certain acids, organic acids, etc. can be effective methods. As reported, Bacillus licheniformis might be useful for ameliorating the adverse influence of heat on the egg production and gut health of laying hens [6], Lactobacillus improved the average daily gain (ADG) of broilers [7], methionine hydroxy analogue alleviated major damage of broilers through the action on some genes related to thioredoxin complex activity [8], and organic acid improved microbiological quality of chicken meat [9]. Numerous studies have reported that dietary organic acid or organic acid salts can improve the growth performance, immune status and gut health of broilers [10, 11]. However, few data are available for their effects on broilers under heat stress [12].

Therefore, the main goal of the present study was to investigate the effects of commercial compound organic acid calcium (COAC) on hepatic antioxidant status and intestinal barrier in male broilers under high ambient temperature.

\section{MATERIALS AND METHODS}

\section{Animals and management}

The experiment was conducted in summer. The experimental use of animals and related procedures were performed in accordance with the Chinese Guidelines for Animal Welfare and approved by the Institutional Animal Care and Use Committee of Zhejiang University (Hangzhou, China).

Nine hundred healthy one-d-old Cobb-500 male broiler chicks with an average initial body weight of $45.60 \pm 0.58 \mathrm{~g}$ were obtained from a commercial hatchery, and randomly distributed into three treatment groups with 6 replicate pens containing 50 birds each. Dietary treatments, with a constant calcium and available phosphorus ratio, were arranged as follows: The control group received the basal diet and the treatment groups received the same basal diet supplemented with $0.4 \%$ and $0.8 \%$ COAC, respectively. The COAC, provided by Hangzhou Guogu Biological Technology Co., Ltd (Zhejiang, China), is a compound acidifier blend of calcium formate, calcium citrate and calcium lactate with 7:2:1 ratio, and a total calcium content at $26.45 \%$. The experimental diets (starter diets from 1 to $21 \mathrm{~d}$; grower-finisher diets from 22 to $42 \mathrm{~d}$ ) were formulated to meet the NRC [13] nutrient recommendations for broilers. Ingredients and chemical composition of the diets are presented in Table 1.

Chicks were handled carefully to avoid any pain or injury and placed in a room with adjoining floor pens (50 birds/pen, $0.28 \mathrm{~m} \times 0.26 \mathrm{~m}$ floor area/bird), which were separated by wire fencing. The room was cleaned and sterilized thoroughly with formaldehyde and potassium permaganate solution $\left(\mathrm{KMnO}_{4}\right.$ + formaldehyde solution) 15 days prior to the arrival of the birds. Birds had ad libitum access to diets (in powder form) and water at a constant mean indoor temperature of $32.7^{\circ} \mathrm{C}$. The relative humidity was kept from $55 \%$ to $65 \%$ (Table 2), and the light is nature lighting. Broilers were raised using common management practice for broiler chicks.

\section{Sample collection and analytical determination}

At $21 \mathrm{~d}$ and $42 \mathrm{~d}$, after a $12 \mathrm{~h}$ feed withdrawn, one bird from each replicate was randomly chosen and killed by cervical dislocation. Then, the liver tissue was collected immediately according to the method of Bai et al [14]. The middle-jejunum and ileum segments were obtained by the method of Adil et al [11]. All samples were quickly snap-frozen in liquid nitrogen and stored at $-80^{\circ} \mathrm{C}$ for further analysis.

\section{Growth performance}

The broilers were weighed at 08:00 am on an empty stomach in terms of replicate at $21 \mathrm{~d}$ and $42 \mathrm{~d}$ respectively. The amount of feed and feed remaining were recorded for each replicate. The ADG, the average daily feed intake (ADFI), the ratio of feed to gain $(F / G)$ were calculated.

\section{Liver biochemical and antioxidant indexes}

Liver samples were homogenized with ice-cold physiologic saline with the ratio of 1:9, then centrifuged at 2,500 r/min for 15 min under $4^{\circ} \mathrm{C}$. The supernatants were collected for the analysis of glutamic oxalacetic transaminase (GOT), aspartate amino transferase (GPT), alkaline phosphatase (AKP), the total antioxidant capacity (T-AOC), total superoxide dismutase (T-SOD), and glutathione peroxidase (GSH-Px) activities, total protein (TP), malondialdehyde (MDA) contents. The kits were provided by Nanjing Jiancheng Biological Engineering Institute (Nanjing, China).

\section{RNA extraction and quantitative real-time polymerase} chain reaction

The mid-jejunum and ileum segments were carefully dissected and rinsed with sterilized saline. Jejunal and ileal mucosa were gently scraped off. All the samples were placed in liquid nitrogen immediately and stored at $-80^{\circ} \mathrm{C}$ till further analysis. Total RNA was extracted using RNAiso Plus method (TaKaRa, Dalian, China). Complementary DNA (cDNA) was synthesized from $1 \mu \mathrm{g}$ of total RNA using M-MLV reverse transcriptase (TaKaRa, China). Transcriptional changes were then identified by quantitative polymerase chain reaction (PCR), which was performed using the Premix Ex TaqTM with SYBR Green (TaKaRa, China) and the ABI 7500 Fast Real-Time PCR system (Applied Biosystemics, Carlsbad, CA, USA). The thermocycle protocol lasted for 
Table 1. Ingredients and nutrient levels of the experimental diets (\%, as fed basis)

\begin{tabular}{|c|c|c|c|c|c|c|}
\hline \multirow{2}{*}{ Items } & \multicolumn{3}{|c|}{ Starter phase $^{1)}(1$ to $21 \mathrm{~d})$} & \multicolumn{3}{|c|}{ Grower-finisher phase $^{1)}$ (22 to 42 d) } \\
\hline & Control & $0.4 \%$ COAC & $0.8 \%$ COAC & Control & $0.4 \%$ COAC & $0.8 \%$ COAC \\
\hline \multicolumn{7}{|l|}{ Ingredients } \\
\hline Corn & 60.00 & 60.00 & 60.00 & 66.00 & 66.00 & 66.00 \\
\hline Soybean meal & 28.50 & 28.50 & 28.50 & 24.00 & 24.00 & 24.00 \\
\hline Fish meal & 2.00 & 2.00 & 2.00 & 1.00 & 1.00 & 1.00 \\
\hline Wheat middlings & 4.50 & 4.50 & 4.50 & 4.00 & 4.00 & 4.00 \\
\hline Salt & 0.30 & 0.30 & 0.30 & 0.30 & 0.30 & 0.30 \\
\hline Choline chloride (50\%) & 0.15 & 0.15 & 0.15 & 0.10 & 0.10 & 0.10 \\
\hline Calcium hydrophosphate & 1.20 & 1.20 & 1.20 & 1.00 & 1.00 & 1.00 \\
\hline Limestone & 1.20 & 0.90 & 0.60 & 1.20 & 0.90 & 0.60 \\
\hline Compound organic acid calcium & 0.00 & 0.40 & 0.80 & 0.00 & 0.40 & 0.80 \\
\hline Zeolite power & 1.15 & 1.05 & 0.95 & 1.40 & 1.30 & 1.20 \\
\hline Premix ${ }^{2)}$ & 1.00 & 1.00 & 1.00 & 1.00 & 1.00 & 1.00 \\
\hline Total & 100.00 & 100.00 & 100.00 & 100.00 & 100.00 & 100.00 \\
\hline \multicolumn{7}{|l|}{ Nutrient levels $s^{3)}$} \\
\hline $\mathrm{ME}(\mathrm{MJ} / \mathrm{kg})$ & 11.73 & 11.73 & 11.73 & 11.91 & 11.91 & 11.91 \\
\hline Crude protein & 18.86 & 18.86 & 18.86 & 16.69 & 16.69 & 16.69 \\
\hline Lysine & 1.21 & 1.21 & 1.21 & 1.08 & 1.08 & 1.08 \\
\hline Methionine & 0.57 & 0.57 & 0.57 & 0.45 & 0.45 & 0.45 \\
\hline Calcium & 0.98 & 1.00 & 0.98 & 0.87 & 0.87 & 0.86 \\
\hline Total phosphorus & 0.70 & 0.70 & 0.70 & 0.61 & 0.61 & 0.61 \\
\hline Aailable phosphorus & 0.46 & 0.46 & 0.46 & 0.39 & 0.39 & 0.39 \\
\hline
\end{tabular}

COAC, compound organic acid calcium; ME, metabolizable energy.

1) Control = basal diet without any feed additive; $0.4 \%$ COAC = basal diet $+0.4 \%$ compound organic acid calcium; $0.8 \%$ COAC $=$ basal diet $+0.8 \%$ compound organic acid calcium.

2) Premix supplied the following per kilogram of diet: vitamin $A$ 25,000 IU; vitamin D 5,000 IU; vitamin E (DL- $\alpha$-tocopheryl acetate), 12.5 IU; vitamin $\mathrm{K}$ (menadione) 1.25 mg; vitamin $B_{1}$ (thiamine) 1.0 mg; vitamin $B_{2}$ (riboflavin) 8 mg; vitamin $B_{6}$ (pyridoxine) $3.0 \mathrm{mg}$; vitamin $B_{12}$ (cyanocobalamin) $15 \mu$; folic acid $250 \mu g$; nicotinic acid $17.5 \mathrm{mg}$; calcium pantothenate 12.5 mg; Fe 80 mg; Cu 10 mg; Mn 80 mg; Zn 80 mg; Se 0.15 mg; I 0.35 mg; phytase $500 \mathrm{U}$.

${ }^{3)}$ Calcium was measured value, while the others were calculated values.

$30 \mathrm{~s}$ at $95^{\circ} \mathrm{C}$, followed by 40 cycles of $5 \mathrm{~s}$ denaturation at $95^{\circ} \mathrm{C}$, $34 \mathrm{~s}$ annealing/extension at $60^{\circ} \mathrm{C}$, and then a final melting curve analysis to monitor purity of the PCR product. Primer sequences are presented in Table 3. The $2^{-\Delta \Delta \mathrm{Ct}}$ method was used to estimate mRNA abundance. $\Delta \mathrm{Ct}$ is $\mathrm{C}_{\mathrm{t} \text {, target }}-\mathrm{C}_{\mathrm{t} \text {, reference }}$ and $\Delta \Delta \mathrm{Ct}$ is $\Delta \mathrm{C}_{\mathrm{t} \text {, treatment }}-\Delta \mathrm{C}_{\mathrm{t}, \text { control }}$. Relative gene expression levels were normalized to those of eukaryotic reference gene $\beta$-actin [15].

\section{Statistical analysis}

After being organized by Microsoft Excel 2003 (Microsoft

Table 2. Mean outdoor and indoor temperature and relative humidity

\begin{tabular}{lccc}
\hline Items & $\begin{array}{c}\text { Mean outdoor } \\
\text { temperature }\left({ }^{\circ} \mathrm{C}\right)\end{array}$ & $\begin{array}{c}\text { Mean indoor } \\
\text { temperature }\left({ }^{\circ} \mathrm{C}\right)\end{array}$ & $\begin{array}{c}\text { Relative } \\
\text { humidity }(\%)\end{array}$ \\
\hline The 1st wk & 29.86 & 30.71 & 55.71 \\
The 2nd wk & 33.21 & 34.00 & 58.43 \\
The 3rd wk & 37.00 & 38.00 & 64.00 \\
The 4th wk & 32.29 & 33.00 & 62.57 \\
The 5th wk & 30.50 & 31.43 & 62.86 \\
The 6th wk & 27.79 & 29.00 & 60.86 \\
Mean & 31.77 & 32.70 & 60.74 \\
\hline
\end{tabular}

Corp., Redmond, WA, USA), the data were analyzed by oneway analysis of variance of the SPSS 20.0 (SPSS Inc., Chicago, IL, USA) followed by a Duncan's multiple range test [16]. The results were expressed in terms of the means plus pooled standard error of means. Significance was declared at $\mathrm{p}<0.05$ and statistical tendencies noted at $0.05<\mathrm{p}<0.10$.

\section{RESULTS}

\section{Growth performance}

Effects of dietary compound organic acid calcium on growth performance of broilers are shown in Table 4 . At 1 to $21 \mathrm{~d}$, the $\mathrm{ADG}$ in $0.4 \% \mathrm{COAC}$ and $0.8 \% \mathrm{COAC}$ were increased by $7.22 \%$ and $6.13 \%(\mathrm{p}<0.05)$ respectively, $\mathrm{F} / \mathrm{G}$ were decreased by $3.47 \%$ and $4.05 \%(\mathrm{p}<0.05)$ respectively compared with control. At 22 to $42 \mathrm{~d}$, the ADG in $0.4 \%$ COAC and $0.8 \%$ COAC were improved by $7.84 \%$ and $7.86 \%(\mathrm{p}<0.05)$ respectively, $F / G$ were reduced by $5.24 \%$ and $4.76 \%(\mathrm{p}<0.05)$ respectively, At 1 to $42 \mathrm{~d}$, the ADG in $0.4 \%$ COAC and $0.8 \%$ COAC were increased by $7.60 \%$ and $7.23 \%(\mathrm{p}<0.05)$ respectively, F/G were decreased by $5.08 \%$ and $4.27 \%(\mathrm{p}<0.05)$ respectively. No remarkable differences $(\mathrm{p}>0.05)$ were ob- 
Table 3. Gene names and primer sequences

\begin{tabular}{|c|c|}
\hline Gene & Primer sequence $5^{\prime}-3^{\prime}$ \\
\hline \multirow[t]{2}{*}{ MUC-2 } & F: GCCTGCCCAGGAAATCAAG \\
\hline & R: CGACAAGTTTGCTGGCACAT \\
\hline \multirow[t]{2}{*}{ Ocln } & F: GAGCCCAGACTACCAAAGCAA \\
\hline & R: GCTTGATGTGGAAGAGCTTGTTG \\
\hline \multirow[t]{2}{*}{ Cldn1 } & F:TGGCCACGTCATGGTATGG \\
\hline & R: AACGGGTGTGAAAGGGTCATAG \\
\hline \multirow[t]{2}{*}{ Cldn3 } & F:AATGCGCCATCTCTGCAAAC \\
\hline & R: GTTTCTCCGCCAGACTCTCC \\
\hline \multirow[t]{2}{*}{$T L R 2$} & F: TGTTCCTGTTCATCCTCATCCT \\
\hline & R:AGTTGGAGTCGTTCTCACTGT \\
\hline \multirow[t]{2}{*}{$\beta$-actin } & F: TATGTGCAAGGCCGGTTTC \\
\hline & R: TGTCTTTCTGGCCCATACCAA \\
\hline \multirow[t]{2}{*}{ TLR4 } & F: GAATGACACGGACACTCTT \\
\hline & R:ACATAGGAACCTCTGACAAC \\
\hline \multirow[t]{2}{*}{ TLR15 } & F: CTTGTCGTTCTGGTGCTAA \\
\hline & R:ATCGTGCTCGCTGTATGA \\
\hline \multirow[t]{2}{*}{$I L-1 \beta$} & F: CGACATCAACCAGAAGTGCTT \\
\hline & R: GTCCAGGCGGTAGAAGATGA \\
\hline \multirow[t]{2}{*}{ iNOS } & F: TACTCTTGGCGTCATTACTC \\
\hline & R: GCATAGATCACAGTCACCTT \\
\hline \multirow[t]{2}{*}{ TGF- $\beta 2$} & F:TCTCGGAGCAGCGGATAGA \\
\hline & R:AATCCAAGGTTCCTGTCTCTGT \\
\hline
\end{tabular}

F, forward; R, reverse; $M U C-2$, mucin 2; Ocln, occluding; Cldn, claudin; TLR, toll-like receptor; IL, interleukin; iNOS, inducible nitric oxide synthase; TGF- $\beta 2$, transforming growth factor-beta 2 . served in ADFI at any stage.

\section{Liver biochemical and antioxidant status}

Effects of treatments on liver biochemical and antioxidant status in broilers at $\mathrm{d} 21$ and $\mathrm{d} 42$ under seasonal heat stress are presented in Table 5. No statistical differences were observed in the indicators of GOT, GPT, TP, and AKP ( $\mathrm{d} 21)$ in liver ( $\mathrm{p}>0.05)$. However, the activity of AKP was significantly lower in $0.4 \%$ COAC compared to $0.8 \%$ COAC and control at 42 day of age $(\mathrm{p}<0.05)$. Although no significant differences were observed in the activities of T-AOC, T-SOD, GSH-Px, and the content of MDA ( $\mathrm{d} 21)$ in liver of broilers at two stages ( $>0.05$ ), the content of MDA was slightly lower in $0.4 \%$ and $0.8 \%$ COAC at 42 days of age compared to control group ( $\mathrm{p}$ $=0.093)$.

\section{The expression of genes related to intestinal physical barrier in jejunum of broilers}

Changes in the mRNA expression of mucin 2 (MUC-2), occludin (ocln), claudin 1 (cldn1), claudin 3 (cldn3) and transforming growth factor-beta $\beta 2$ (TGF- $\beta 2$ ) in jejunum of broilers are shown in Figure 1. Compared with control group, at d 21, jejunal cldn 3 and TGF- $\beta 2$ mRNA expressions of birds fed $0.8 \%$ COAC were significantly decreased $(\mathrm{p}<0.05)$, while no remarkable differences $(\mathrm{p}>0.05)$ were observed on ocln, $c l d n 1$ transcriptions among all groups $(\mathrm{p}>0.05)$. At $\mathrm{d} 42$, $0.4 \%$ COAC significantly increased $(\mathrm{p}<0.05)$ the MUC-2

Table 4. Effects of dietary compound organic acid calcium on growth performance of broilers

\begin{tabular}{|c|c|c|c|c|c|}
\hline \multirow{2}{*}{ Items } & \multicolumn{3}{|c|}{21 days of age $\mathrm{e}^{1)}$} & \multirow{2}{*}{ SEM } & \multirow{2}{*}{$\mathrm{p}$-value } \\
\hline & Control & $0.4 \%$ COAC & $0.8 \%$ COAC & & \\
\hline \multicolumn{6}{|l|}{ Body weight (g) } \\
\hline 1 day of age & 45.80 & 45.19 & 45.40 & 0.35 & 0.52 \\
\hline 21 days of age & $563.45^{\mathrm{a}}$ & $600.15^{b}$ & $594.71^{b}$ & 9.91 & 0.04 \\
\hline 42 days of age & $1,498.89^{\mathrm{a}}$ & $1,608.86^{b}$ & $1,603.45^{b}$ & 35.31 & 0.01 \\
\hline \multicolumn{6}{|l|}{1 to 21 days of age } \\
\hline ADFI (g) & 42.68 & 44.02 & 43.43 & 0.74 & 0.50 \\
\hline$A D G(g)$ & $24.65^{\mathrm{a}}$ & $26.43^{b}$ & $26.16^{b}$ & 0.48 & 0.04 \\
\hline$F / G$ & $1.73^{b}$ & $1.67^{\mathrm{a}}$ & $1.66^{b}$ & 0.01 & 0.01 \\
\hline \multicolumn{6}{|c|}{22 to 42 days of age } \\
\hline ADFI (g) & 93.43 & 95.59 & 95.98 & 1.62 & 0.55 \\
\hline$A D G(g)$ & $44.54^{\mathrm{a}}$ & $48.03^{b}$ & $48.04^{b}$ & 1.51 & 0.02 \\
\hline$F / G$ & $2.10^{b}$ & $1.99^{\mathrm{a}}$ & $2.00^{\mathrm{a}}$ & 0.04 & 0.01 \\
\hline \multicolumn{6}{|l|}{1 to 42 days of age } \\
\hline ADFI (g) & 67.99 & 69.77 & 69.71 & 0.95 & 0.37 \\
\hline$A D G(g)$ & $34.60^{\mathrm{a}}$ & $37.23^{b}$ & $37.10^{b}$ & 0.85 & 0.01 \\
\hline$F / G$ & $1.97^{b}$ & $1.87^{\mathrm{a}}$ & $1.88^{\mathrm{a}}$ & 0.03 & 0.02 \\
\hline
\end{tabular}

Values reported as means $(n=6)$.

COAC, compound organic acid calcium; SEM, standard error of means for 6 broilers each; ADFl, the average daily feed intake; ADG, the average daily gain; F/G, the ratio of feed gain.

1) Control = basal diet without any feed additive; $0.4 \%$ COAC $=$ basal diet $+0.4 \%$ compound organic acid calcium; $0.8 \%$ COAC $=$ basal diet $+0.8 \%$ compound organic acid calcium.

a,b Means in the same row with different superscripts differ statistically $(p<0.05)$. 
Table 5. Effects of dietary compound organic acid calcium supplementation on liver biochemical and antioxidant status in broilers under seasonal heat stress

\begin{tabular}{|c|c|c|c|c|c|c|c|c|c|c|}
\hline \multirow{2}{*}{ Items } & \multicolumn{3}{|c|}{21 days of age ${ }^{1)}$} & \multirow{2}{*}{ SEM } & \multirow{2}{*}{$p$-value } & \multicolumn{3}{|c|}{42 days of age ${ }^{1)}$} & \multirow{2}{*}{ SEM } & \multirow{2}{*}{$\mathrm{p}$-value } \\
\hline & Control & $0.4 \%$ COAC & $0.8 \% \mathrm{COAC}$ & & & Control & $0.4 \%$ COAC & $0.8 \%$ COAC & & \\
\hline \multicolumn{11}{|c|}{ Biochemical constituents } \\
\hline GOT (U/L) & 29.87 & 30.48 & 35.28 & 2.648 & 0.302 & 20.55 & 19.95 & 20.5 & 0.833 & 0.867 \\
\hline GPT (U/L) & 2.2 & 1.54 & 1.26 & 0.35 & 0.141 & 2.43 & 1.70 & 2.46 & 0.473 & 0.461 \\
\hline $\operatorname{AKP}(\mathrm{U} / \mathrm{L})$ & 17.07 & 19.63 & 17.06 & 2.106 & 0.672 & $87.32^{b}$ & $65.93^{\mathrm{a}}$ & $94.29^{b}$ & 8.007 & 0.022 \\
\hline $\mathrm{TP}(\mathrm{g} / \mathrm{L})$ & 11.12 & 11.5 & 11.69 & 1.27 & 0.700 & 10.81 & 10.86 & 19.96 & 1.260 & 0.970 \\
\hline \multicolumn{11}{|c|}{ Antioxidants enzymes } \\
\hline $\mathrm{T}-\mathrm{AOC}(\mathrm{U} / \mathrm{mL})$ & 1.39 & 1.53 & 1.46 & 0.062 & 0.282 & 2.34 & 2.96 & 2.53 & 0.419 & 0.626 \\
\hline T-SOD (U/mL) & 295.09 & 324.75 & 323.76 & 20.788 & 0.584 & 95.06 & 99.43 & 104.08 & 7.534 & 0.755 \\
\hline GSH-Px (U/L) & 23.02 & 23.06 & 23.15 & 1.453 & 0.998 & 25.97 & 24.03 & 29.9 & 3.194 & 0.476 \\
\hline $\mathrm{MDA}(\mathrm{nmol} / \mathrm{mL})$ & 0.57 & 0.38 & 0.45 & 0.071 & 0.143 & 2.02 & 1.62 & 1.31 & 0.236 & 0.093 \\
\hline
\end{tabular}

Values reported as means $(n=6)$.

COAC, compound organic acid calcium; SEM, standard error of means for 6 broilers each; GOT, glutamic oxalacetic transaminase; GPT, aspartate amino transferase; AKP, alkaline phosphatase; TP, total protein; T-AOC, total antioxidant capacity; T-SOD, total superoxide dismutase; GSH-Px, glutathione peroxidase; MDA, malondialdehyde.

${ }^{1)}$ Control = basal diet without any feed additive; $0.4 \%$ COAC $=$ basal diet $+0.4 \%$ compound organic acid calcium; $0.8 \%$ COAC $=$ basal diet $+0.8 \%$ compound organic acid calcium.

$a, b$ Means in the same row with different superscripts differ statistically $(p<0.05)$.

and TGF- $\beta 2$ expressions, whereas, $0.8 \%$ COAC reduced $(\mathrm{p}<0.05)$ the $c l d n 1$ and $T G F-\beta 2$ expressions.

The expression of genes related to intestinal physical barrier in ileum of broilers

Effect of dietary COAC on the mRNA expressions of MUC2, ocln, $c l d n 1, c l d n 3$, and TGF- $\beta 2$ in ileum of broilers are shown in Figure 2. At d 21, the mRNA expressions of ocln and $c l d n 3$ in ileum were significantly higher $(\mathrm{p}<0.05)$ in birds fed $0.4 \%$ COAC than control group. Compared with control and $0.4 \%$ COAC, birds in $0.8 \%$ COAC had a lower cldn 3 expression and a higher MUC-2 expression ( $\mathrm{p}<0.05)$. At $\mathrm{d} 42,0.4 \%$ COAC obviously elevated $(\mathrm{p}<0.05)$ the mRNA expression of $o c h$ and $c l d n 1$ compared with $0.8 \%$ COAC.

\section{The expression of genes related to intestinal} immunological barrier in jejunum of broilers

Figure 3 shows the changes in the mRNA expression of toll-like receptor (TLR), nitric oxide synthase (iNOS) and interleukin$1 \beta(I L-1 \beta)$ in jejunum of broilers. Compared with control group, at d 21, 0.4\% COAC significantly decreased $(\mathrm{p}<0.05)$ TLR-2 transcription, and $0.8 \%$ COAC notably increased $(\mathrm{p}<0.05)$ iNOS expression. At $\mathrm{d} 42$, birds fed $0.4 \%$ COAC had significantly decreased the mRNA expression of TLR$15(\mathrm{p}<0.05)$, while no significant differences were observed in other gene expressions among all treatments $(\mathrm{p}>0.05)$.

\section{The expression of genes related to intestinal} immunological barrier in ileum of broilers

As shown in Figure 4, at d 21, compared with control group, the COAC groups reduced $i N O S$ expressions and $0.4 \%$ COAC obviously decreased TLR-15 expression $(\mathrm{p}<0.05)$. At $\mathrm{d} 42$, birds fed $0.8 \%$ COAC had significantly decreased $(\mathrm{p}<0.05)$ mRNA expression of $i N O S$. No significant differences were observed on the mRNA expressions of TLR-2, TLR-4, and $I L-1 \beta$ among all treatments ( $>0.05)$.

\section{DISCUSSION}

The addition of acidifiers or organic acid salts to broiler diets beneficially improves the palatability of the diet while participating in the body's metabolic response and accelerating the body's absorption of nutrients [17]. Thereby promoting broiler weight gain and reducing F/G. Some studies reported that dietary supplemented organic acids can significantly increase daily gain and feed conversion in broilers [10], which is agreement with our results. In the present study, there was no significant difference in ADFI observed between experiment groups, which is consistent with studies reported by Sultan et al [18] and Gunal et al [19]. While, the studies by Chowdhury et al [10] and Haque et al [20] showed that the addition of organic acids to the diet increased the feed intake of broilers. And other studies found that dietary supplement organic acids reduced the feed intake of broilers [17,21], which might be related to the type of organic acid, the amount of addition, the feeding environment and the feeding method $[18,20,22]$.

The structure and physiology of the cells can be affected by high temperature, causing impairment of transcription, oxidative metabolism, membrane structure and function [23] and gene expression [2]. Also, heat stress can result in oxidative stress and induce cells to generate small amounts of free radicals or reactive oxygen species (ROS) [5], which may damage biological macro-molecules and tissues if not con- 
A

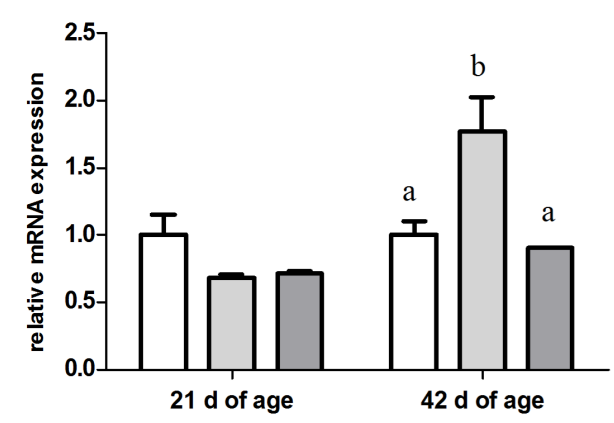

C

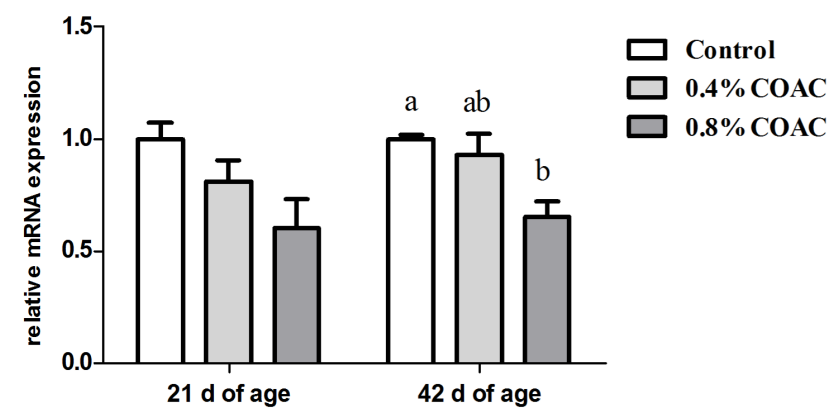

$\mathbf{E}$

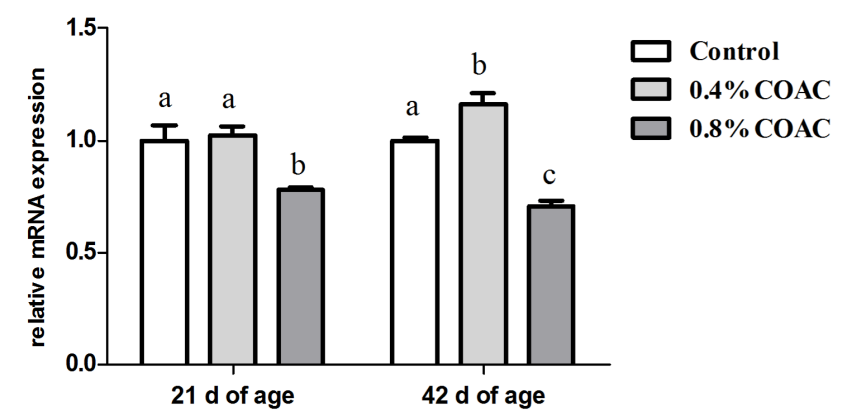

B

ocln

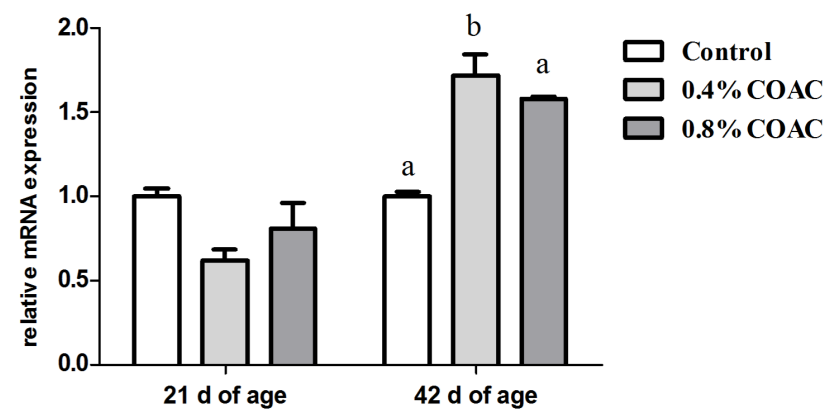

D

cldn3

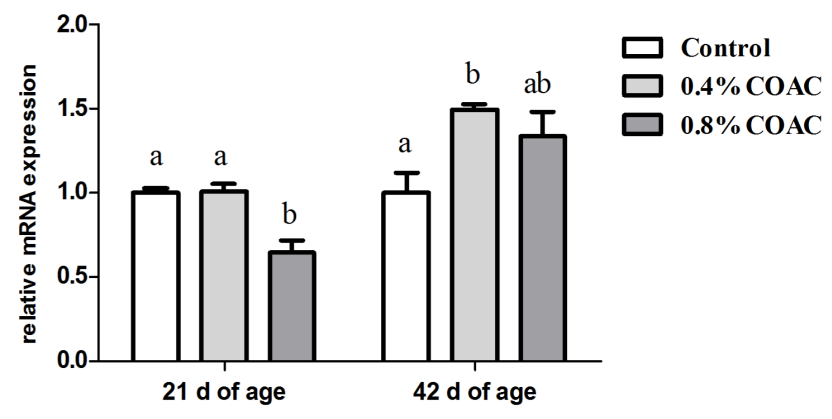

Figure 1. Effects of compound organic acid calcium on MUC-2, ocln, cldn1, cldn3 and TGF- $\beta 2$ mRNA expression in jejunum of broilers. At 21 and 42 days of age, the expression of MUC-2 (A), ocln (B), cldn1 (C), cldn3 (D) and TGF- $\beta 2$ (E) were measured by real-time polymerase chain reaction. MUC-2, mucin 2; Ocln, occluding; Cldn, claudin; TGF- $\beta 2$, transforming growth factor-beta 2. Different letters $(a-c)$ denote a statistical difference $(p<0.05)$.

trolled [24]. However, these damages might be minimized via antioxidant defense systems, including antioxidant enzymes such as SOD, GSP-Px, etc. [25]. The biochemical and antioxidant indices play a vital role in protecting cellular and tissue damage from harmful effects of ROS [25], and are usually used as indicators of the health condition of animals [5]. The activities of GOT and GPT can reflect the functions and integrity of tissues like liver [26]. AKP performs lipid transportation in the intestine, calcification in bone and is present in liver, and usually remains normal or moderately increased in acute viral hepatitis [27], decreased in hypothyroidism and pernicious anaemia [28]. In the present study, COAC did not influence the activities of GOT, GPT, TP, and AKP in liver at $\mathrm{d} 21$. While the AKP activity was significantly decreased in $0.4 \%$ COAC, which may be have a protective effect in the liver. $\mathrm{MDA}$, one of the important metabolites of lipid peroxidation, can serve as an indicator of tissue injury. The antioxidant enzymes like T-AOC, T-SOD, and GSH-Px can minimize the 
A

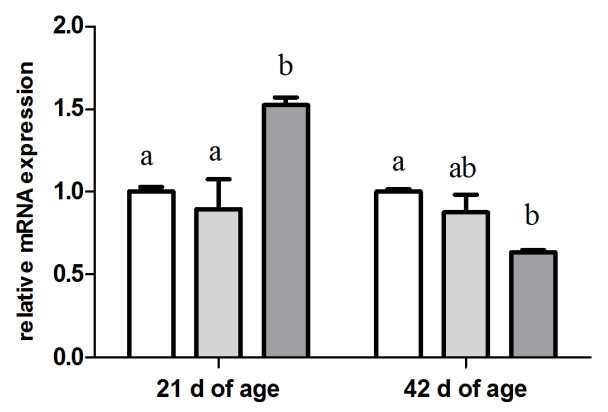

C

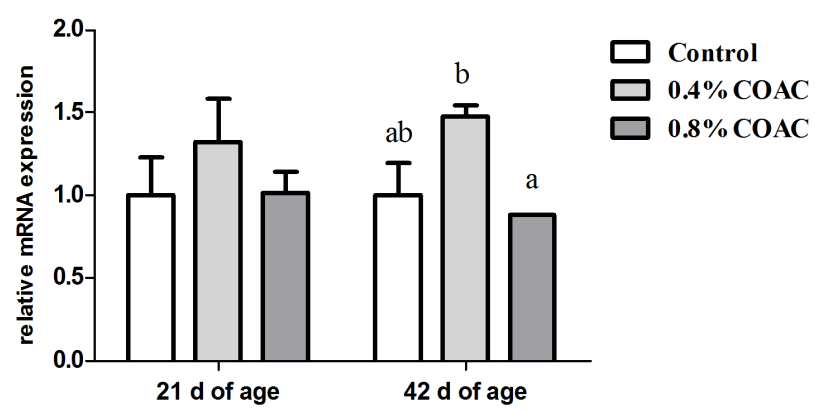

$\mathbf{E}$

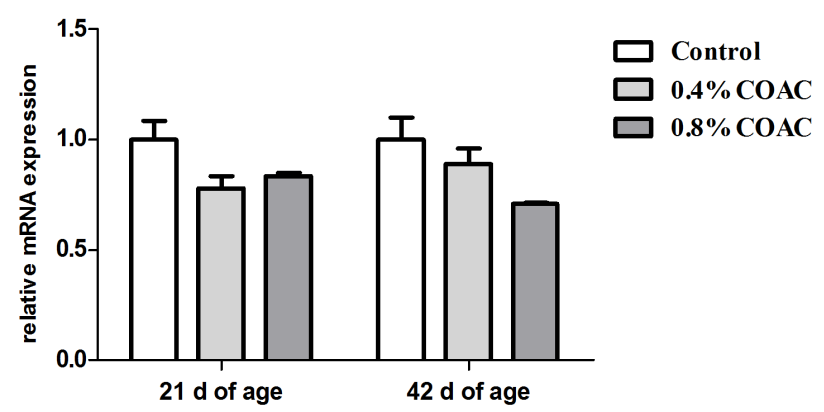

B ocln

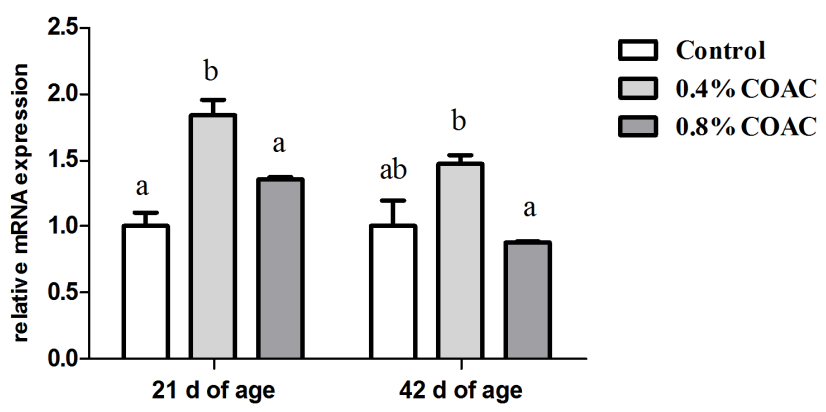

D

cldn3

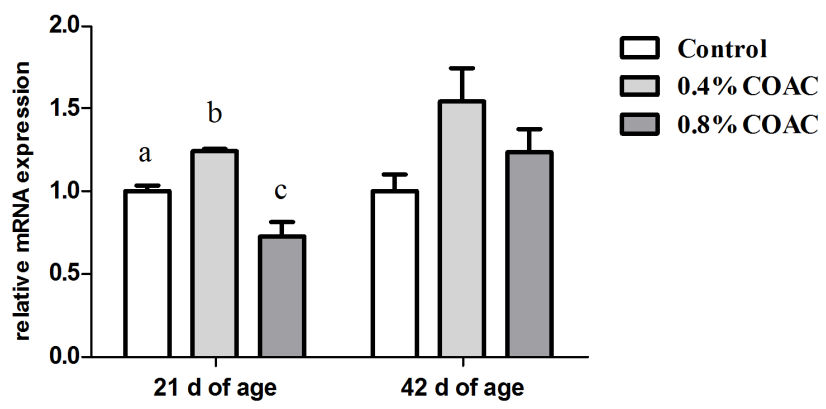

Figure 2. Effects of compound organic acid calcium on ocln, cldn1, cldn3 and TGF- $\beta 2$ mRNA expression in ileum of broilers. At 21 and 42 days of age, the expression of ocln (A), cldn1 (B), cldn3 (C) and TGF- $\beta 2$ (D) were measured by real-time polymerase chain reaction. Ocln, occluding; Cldn, claudin; TGF- $\beta 2$, transforming growth factorbeta 2. Different letters $(a-c)$ denote a statistical difference $(p<0.05)$.

oxidative damage by protecting the cell against cellular oxidants and preventing the accumulation of oxidatively injured molecules [29]. Although no significant differences were observed on the activities of T-AOC, T-SOD, and GSH-Px along with the content of MDA ( $\mathrm{d} 21$ ) in liver of broilers, the content of MDA was slightly lower in both $0.4 \%$ and $0.8 \%$ COAC compared with control group, which is in agreement with the results of Seven et al [29] and Ma et al [30] where heat stress increased the concentration of MDA in liver of both broilers and laying hens.

The integrity of the seal of the paracellular pathway between cells is crucial for the epithelial cell layer to function properly [15], and this seal is achieved by a physical barrier, especially tight junctions [31]. The functional barrier of the intestinal epithelial separates the intestine from the outside world, and requires the formation of tight junctions that allow cells to adhere tightly to each other and control the intestinal permeability [32]. Tight junctions such as ocln, and cldn are structural 
A

TLR-2

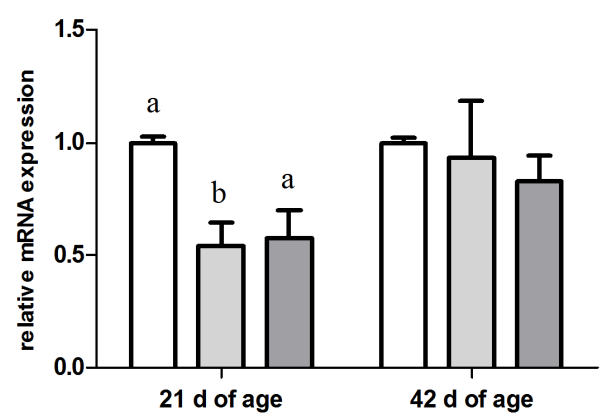

C

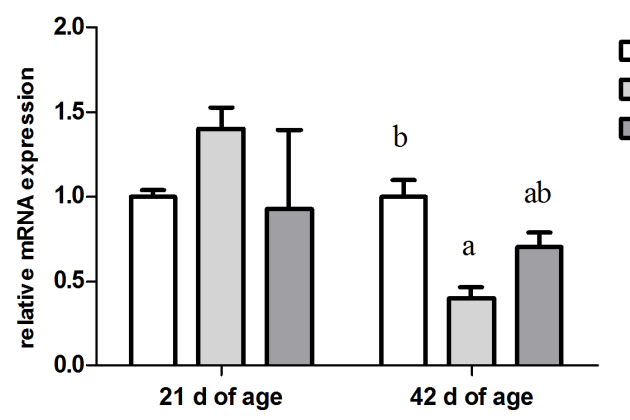

$\mathbf{E}$

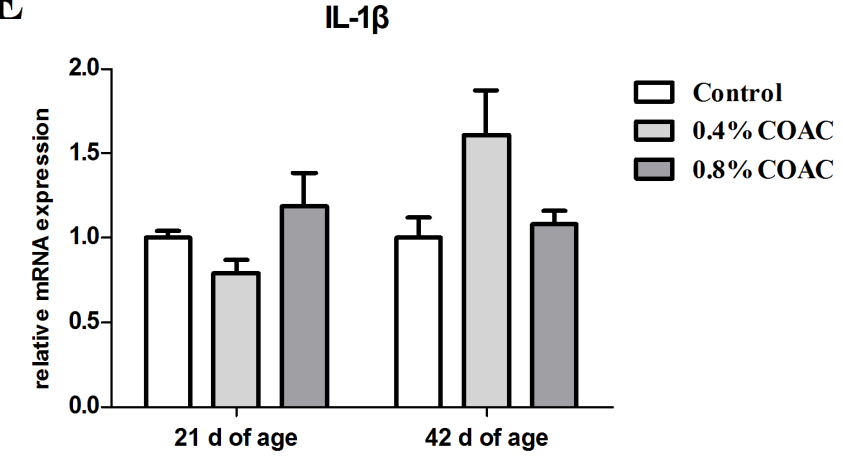

B TLR-4

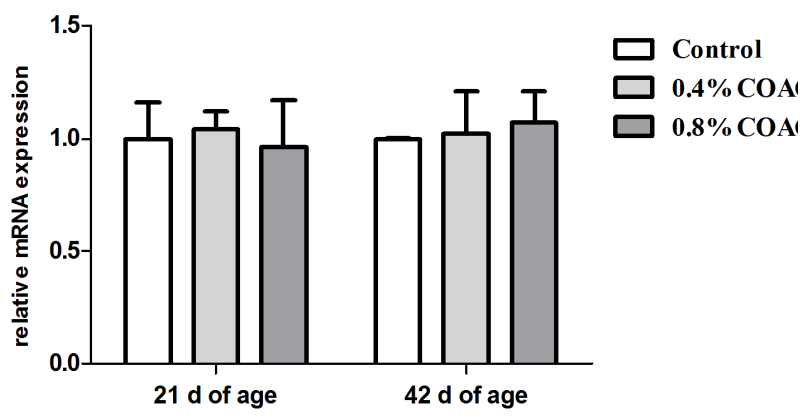

D iNOS

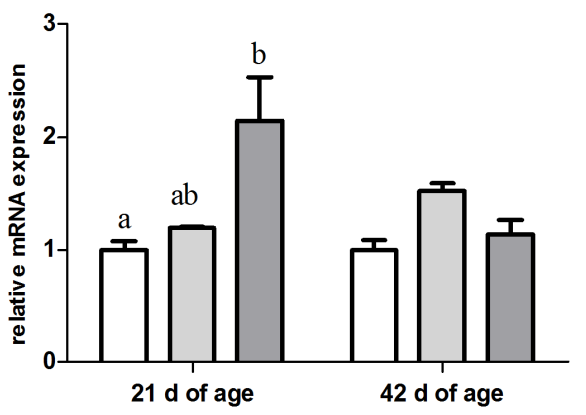

Figure 3. Effects of compound organic acid calcium on TLR, iNOS and IL-1 $\beta$ mRNA expression in jejunum of broilers. At 21 and 42 days of age, the expression of TLR-2 (A), TLR-4 (B), TLR-15 (C), iNOS (D) and IL-1 $\beta$ (E) were measured by real-time polymerase chain reaction. TLR, toll-like receptor; iNOS, inducible nitric oxide synthase; IL-1 $\beta$, interleukin $1 \beta$. Different letters $(a, b)$ denote a statistical difference $(p<0.05)$.

and functional proteins [15], among which the most abundant mucin is MUC-2, that can create the first line of defense against microbial encroachment [33]. In the present study, the transcript levels of all the tested tight junctions were upregulated by $\mathrm{COAC}$ and the effect was more obvious when birds were fed 0.4\% COAC. A damaged intestinal epithelial integrity may facilitate the invasion of endotoxins from gut microbes, leading to a local imbalance of anti- and pro-in- flammatory molecules in the intestines [34]. COAC improved the intestinal physical barrier and may also participate in enhancing the intestinal immunological barrier function.

In addition, TLRs are a group of evolutionarily conserved membrane receptors broadly expressed on various innate immunity cells and non-immune cells, they function as primary sensors that can initiate innate immune responses via responding to pathogen-associated molecular patterns from 
A

TLR-2

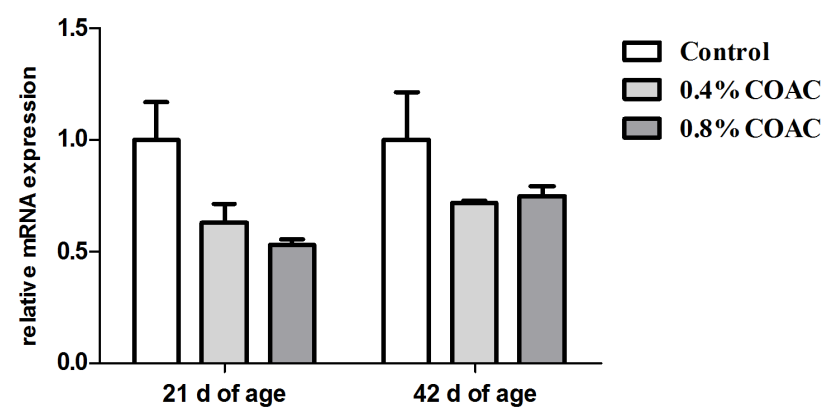

C

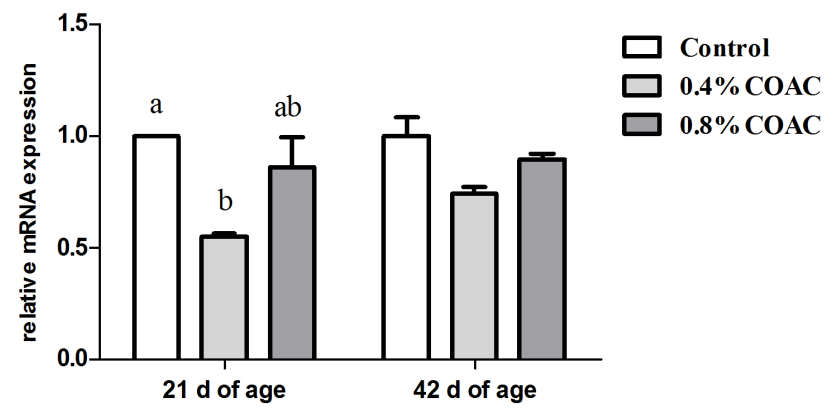

E

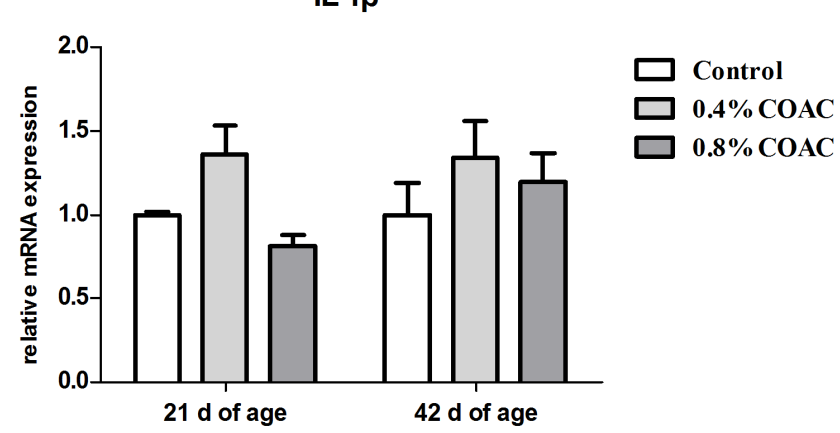

B TLR-4

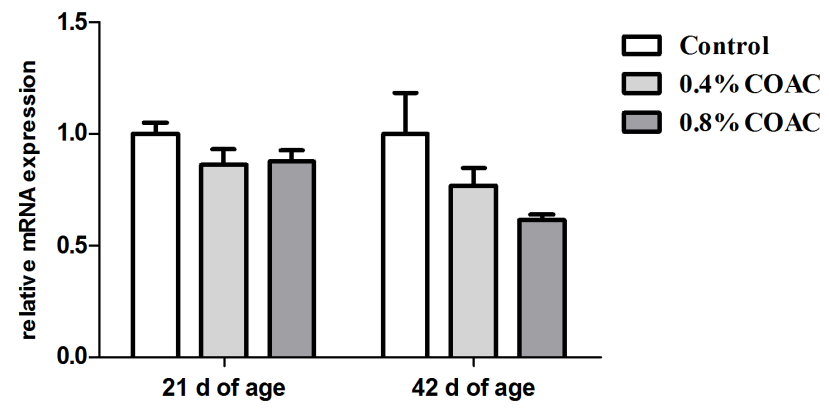

D

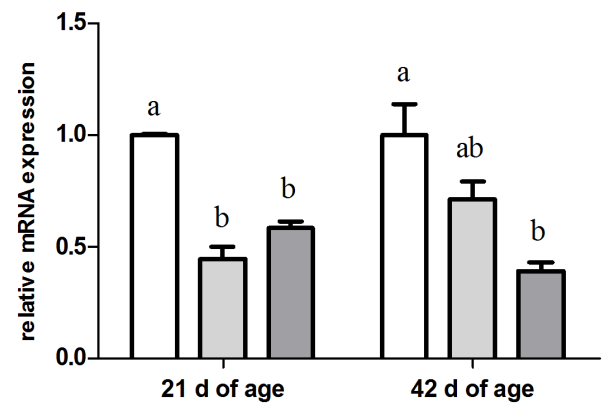

Figure 4. Effects of compound organic acid calcium on TLR, iNOS, and IL-1 $\beta$ mRNA expression in ileum of broilers. At 21 and 42 days of age, the expression of TLR-2 (A), TLR-4 (B), TLR-15 (C), iNOS (D), and IL-1 $\beta$ (E) were measured by real-time polymerase chain reaction. TLR, toll-like receptor; iNOS, inducible nitric oxide synthase; IL, interleukin. Different letters $(a, b)$ denote a statistical difference $(p<0.05)$.

bacteria, viruses, etc. [35]. Moreover, these TLRs such as TLR2 and TLR4 are expressed in pro-inflammatory macrophages and vascular, which would release more TLRs when tissues were injured [36], as $i N O S$ and $I L-1 \beta$. In the current study, we found that COAC significantly decreased the expressions of TLR-2, TLR-15 and pro-inflammatory cytokine iNOS, which might be related to the stimulation of organic acid calcium on immune related organs [37].

\section{CONCLUSION}

Dietary supplementation of compound organic acid calcium can improve the growth performance and alleviate the damages in broilers under heat stress. The effect was demonstrated by increasing the immunological competence, regulating TLR-2, TLR-4, and MUC-2 expressions, resulting in the improvement of broilers tolerance to the damages in liver and 
small intestine. However, only limited studies on the molecular mechanism of dietary organic acid or organic acid salts against the damage of heat stress in broilers have been carried out, which needs further exploration.

\section{CONFLICT OF INTEREST}

We certify that there is no conflict of interest with my financial organization regarding the material discussed in the manuscript.

\section{ACKNOWLEDGEMENTS}

This work was supported by the key Projects of Science and Technology Plan of Zhejiang Province, China (No. 2015C02022) and Hangzhou Guogu Biological Technology Co., Ltd., Zhejiang, P. R. China.

\section{REFERENCES}

1. Hosseini-Vashan SJ, Golian A, Yaghobfar A. Growth, immune, antioxidant, and bone responses of heat stress-exposed broilers fed diets supplemented with tomato pomace. Int J Biometeorol 2016;60:1183-92. https://doi.org/10.1007/s00484-015-1112-9

2. Habashy WS, Milfort MC, Fuller AL, Attia YA, Rekaya R, Aggrey SE. Effect of heat stress on protein utilization and nutrient transporters in meat-type chickens. Int J Biometeorol 2017;61:2111-8. https://doi.org/10.1007/s00484-017-1414-1

3. Loyau T, Berri C, Bedrani L, et al. Thermal manipulation of the embryo modifies the physiology and body composition of broiler chickens reared in floor pens without affecting breast meat processing quality. J Anim Sci 2013;91:3674-85. https://doi.org/10.2527/jas.2013-6445

4. Zaboli GR, Rahimi S, Shariatmadari F, Torshizi MAK, Baghbanzadeh A, Mehri M. Thermal manipulation during pre and post-hatch on thermotolerance of male broiler chickens exposed to chronic heat stress. Poult Sci 2017;96:478-85. https:// doi.org/10.3382/ps/pew344

5. Attia YA, Al-Harthi MA, El-Shafey AS, Rehab YA, Kim WK. Enhancing tolerance of broiler chickens to heat stress by supplementation with vitamin $\mathrm{E}$, vitamin $\mathrm{C}$ and/or probiotics. Ann Anim Sci 2017;17:1155-69. https://doi.org/10.1515/ aoas-2017-0012

6. Deng W, Dong XF, Tong JM, Zhang Q. The probiotic Bacillus licheniformis ameliorates heat stress-induced impairment of egg production, gut morphology, and intestinal mucosal immunity in laying hens. Poult Sci 2012;91:575-82. https://doi. org/10.3382/ps.2010-01293

7. Jahromi MF, Altaher YW, Shokryazdan P, et al. Dietary supplementation of a mixture of Lactobacillus strains enhances performance of broiler chickens raised under heat stress conditions. Int J Biometeorol 2016;60:1099-110. https://doi.org/
10.1007/s00484-015-1103-X

8. Gasparino E, Vesco APD, Khatlab AS, Zancanela V, Grieser DO, Silva SCC. Effects of methionine hydroxy analogue supplementation on the expression of antioxidant-related genes of acute heat stress-exposed broilers. Animal 2018;12:931-9. https://doi.org/10.1017/S1751731117002439

9. Mastrangelo G, Marangi G, Ballarin MN, et al. The effects of organic acid and Origanum onites supplementations on some physical and microbial characteristics of broiler meat obtained from broilers kept under seasonal heat stress. Kafkas Univ Vet Fak 2010;16:S41-6.

10. Chowdhury R, Islam KMS, Khan MJ, et al. Effect of citric acid, avilamycin, and their combination on the performance, tibia ash, and immune status of broilers. Poult Sci 2009;88:1616-22. https://doi.org/10.3382/ps.2009-00119

11. Adil S, Banday T, Bhat GA, Mir MS, Rehman M. Effect of dietary supplementation of organic acids on performance, intestinal histomorphology, and serum biochemistry of broiler chicken. Vet Med Int 2010;78: Article ID479485. https://doi. org/10.4061/2010/479485

12.Attia YA, Abd El-Hamid AE, Ellakany HF, Bovera F, AlHarthi MA, Ghazaly SA. Growing and laying performance of Japanese quail fed diet supplemented with different concentrations of acetic acid. Ital J Anim Sci 2013;12:e37. https:// doi.org/10.4081/ijas.2013.e37

13. National Research Council. Nutrient requirements of poultry: 9th Revised Edition. Washington, DC, USA: National Academy Press; 1994;3:101. https://doi.org/10.1093/japr/3.1.101

14. Bai SP, Wu AM, Ding XM, et al. Effects of probiotic-supplemented diets on growth performance and intestinal immune characteristics of broiler chickens. Poult Sci 2013;92:663-70. https://doi.org/10.3382/ps.2012-02813

15. Wang Y, Du W, Lei K, et al. Effects of dietary Bacillus licheniformis on gut physical barrier, immunity, and reproductive hormones of laying hens. Probiotics Antimicrob Proteins 2017;9:292-9. https://doi.org/10.1007/s12602-017-9252-3

16. Duncan DB. Multiple range and multiple F tests. Biometrics 1955;11:1-42. https://www.jstor.org/stable/3001478

17.Paul SK, Halder G, Mondal MK, Samanta G. Effect of organic acid salt on the performance and gut health of broiler chicken. J Poult Sci 2007;44:389-95. https://doi.org/10.2141/jpsa.44.389

18.Sultan A, Ullah T, Khan S, Khan RU. Effect of organic acid supplementation on the performance and ileal microflora of broiler during finishing period. Pak J Zool 2015;47:635-9.

19. Gunal M, Yayli G, Kaya O, Karahan N, Sulak O. The effects of antibiotic growth promoter, probiotic or organic acid supplementation on performance, intestinal microflora and tissue of broilers. Int J Poult Sci 2006;5:149-55. https://doi.org/10. 3923/ijps.2006.149.155

20. Haque MN, Islam KMS, Akbar MA, et al. Effect of dietary citric acid, flavomycin and their combination on the performance, tibia ash and immune status of broiler. Can J Anim 
Sci 2010;90:57-63. https://doi.org/10.4141/CJAS09048

21. Rahman A, Saima; Pasha TN, Akram M, Abbas Y, Ullah S. Supplementation of exogenous enzymes and organic acid in broiler diets. Eurasian J Vet Sci 2015;31:163-9.

22. Garcia V, Catala-Gregori P, Hernandez F, Megias MD, Madrid J. Effect of formic acid and plant extracts on growth, nutrient digestibility, intestine mucosa morphology, and meat yield of broilers. J Appl Poult Res 2007;16:555-62. https://doi.org/ 10.3382/japr.2006-00116

23. Iwagami Y. Changes in the ultrastructure of human cells related to certain biological responses under hyperthermic culture conditions. Hum Cell 1996;9:353-66.

24. Matés JM, Pérez-Gómez C, Castro IND. Antioxidant enzymes and human diseases. Clin Biochem 1999;32:595-603. https:// doi.org/10.1016/S0009-9120(99)00075-2

25. Altan Ö, Pabuçcuoğlu A, Altan A, Konyalioğlu S, Bayraktar H. Effect of heat stress on oxidative stress, lipid peroxidation and some stress parameters in broilers. Br Poult Sci 2003;44: 545-50. https://doi.org/10.1080/00071660310001618334

26. Adeyemi OT, Osilesi O, Adebawo OO, Onajobi FD, Oyedemi SO, Afolayan AJ. Alkaline phosphatase (ALP), aspartate aminotransferase (AST) and alanine aminotransferase (ALT) activities in selected tissues of rats fed on processed atlantic horse mackerel (Trachurus trachurus). Adv Biosci Biotechnol 2015;6:139-52. http:/dx.doi.org/10.4236/abb.2015.63014

27.Gowda S, Desai PB, Hull VV, Math AAK, Vernekar SN, Kulkarni SS. A review on laboratory liver function tests. Pan Afr Med J 2009;3:17.

28. Simko V. Alkaline phosphatases in biology and medicine. Dig Dis 1991;9:189-209. https://doi.org/10.1159/000171304

29. Seven PT, Yllmaz S, Seven I, Cercı IH, Azman MA, Yilmaz M. Effects of propolis on selected blood indicators and antioxidant enzyme activities in broilers under heat stress. Acta Vet Brno 2009;78:75-83. https://doi.org/10.2754/avb200978010075
30.Ma D, Shan A, Chen Z, et al. Effect of Ligustrum lucidum and Schisandra chinensis on the egg production, antioxidant status and immunity of laying hens during heat stress. Arch Anim Nutr 2005;59:439-47. https://doi.org/10.1080/1745039050035 3499

31. Anderson JM, Van Itallie CM, Fanning AS. Setting up a selective barrier at the apical junction complex. Curr Opin Cell Biol 2004;16:140-5. https://doi.org/10.1016/j.ceb.2004.01.005

32.Zihni C, Balda MS, Matter K. Signalling at tight junctions during epithelial differentiation and microbial pathogenesis. J Cell Sci 2014;127:3401-13. https://doi.org/10.1242/jcs.145029

33. Peterson LW, Artis D. Intestinal epithelial cells: regulators of barrier function and immune homeostasis. Nat Rev Immunol 2014;14:141-53. https://doi.org/10.1038/nri3608

34.Deng W, Dong XF, Tong JM, Zhang Q. The probiotic Bacillus licheniformis ameliorates heat stress-induced impairment of egg production, gut morphology, and intestinal mucosal immunity in laying hens. Poult Sci 2012;91:575-82. https://doi. org/10.3382/ps.2010-01293

35. Wu Y, Shao Y, Song B, et al. Effects of Bacillus coagulans supplementation on the growth performance and gut health of broiler chickens with Clostridium perfringens -induced necrotic enteritis. J Anim Sci Biotechnol 2018;9:9. https://doi.org/10. 1186/s40104-017-0220-2

36. Monaco C, Gregan SM, Navin TJ, Foxwell BM, Davies AH, Feldmann M. Toll-like receptor-2 mediates inflammation and matrix degradation in human atherosclerosis. Circulation 2009;120:2462-9. https://doi.org/10.1161/circulationaha.109. 851881

37. Mohamed MA, El-Daly EF, El-Azeem NAA, Youssef AW, Hassan HMA. Growth performance and histological changes in ileum and immune related organs of broilers fed organic acids or antibiotic growth promoter. Int J Poult Sci 2014;13: 602-10. https://doi.org/10.3923/ijps.2014.602.610 